\title{
A New Approach for Measuring Shareholder Value Creation
}

\author{
Eleftherios Aggelopoulos \\ University of Patras, Greece \\ Dimitris Grypeos \\ Dolphin Capital Partners, Athens, Greece
}

\begin{abstract}
This paper introduces a new approach for measuring shareholder value creation (called adjusted economic profit (EP)) which combines the advantages of both EP and APV (adjusted present value) methods. In particular, the shareholder value creation over a period is derived as the sum of two components: the EP relating purely to the operations of the company and the EP generated each period due to the tax benefit that arises from debt financing. We consider our results to be important for analysts and decision makers involved in appraising business performance or making investment decisions and HR professionals as well.
\end{abstract}

Keywords: value creation, performance measurement, business valuation, residual income (RI) approaches, economic profit (EP), adjusted present value (APV)

\section{Introduction}

The literature applies cash flow (CF) oriented approaches (weighted average cost of capital (WACC) approach, adjusted present value (APV) ${ }^{1}$, flow to equity (FTE)) and residual income (RI) oriented approaches (economic profit (EP), economic value added $(\mathrm{EVA})^{2}$ ) to company valuation (Copeland, Koller, \& Murrin, 2000). The principle of one value suggests that all methods should yield the same result as long as the same assumptions are utilized (Adsera \& Vinolas, 2003) and are applied consistently. Astute readers recognize that all aforementioned approaches are complementary and provide an insight into different facets of the value of a business.

Regarding the CF approaches, both WACC and APV are designed to value operations or assets in place. The main difference is placed on the details of their execution and especially how these two methods account for the value created or destroyed by financial maneuvers, as opposed to operations. Specifically, APV approach's ability to analyze financial side effects separately and then add their value to that of the business offers a competitive advantage to APV relative to WACC approach where financial effects are valued in the cost of capital (Luehrman, 1997). The main disadvantage of CF approaches (including APV) is that they cannot be applied to performance measurement since each period's CF provides little insight into the company's performance.

Eleftherios Aggelopoulos, Ph.D., adjunct lecturer in Financial Accounting, Department of Business Administration, University of Patras. Email: eaggelopoulos@upatras.gr.

Dimitris Grypeos, MSc, associate at Dolphin Capital Partners.

1 The use of the Franco Modigliani and Merton Miller valuation framework (M\&M) by Stewart Myers (1974), in order to examine the interactions between the investment decision and the financing decision, has come to be called APV or the valuation-by-components method (Booth, 2002).

2 Forms of RI appear under various names, such as EVA (trademark of Stern Stewart and Co.), EP (developed by McKinsey and Co., Inc.), and abnormal earnings (Feltham \& Ohlson, 1995). EVA and EP differ in their definition of operating earnings, invested capital, and cost of equity. However, these differences are very much of a minor nature and the concepts are often identical in practice (Gross, 2006). For the remainder of this paper, we shall use these terms interchangeably. 
On the other hand, RI-oriented approaches can be used to measure the value of an enterprise (leading to identical results with CF approaches given the same assumptions), as well as the periodic performance of it ${ }^{3}$. In general, RI can be understood as an extension of the CF approach that improves the measurement and management of shareholder value creation. Consequently, RI is a useful concept for value-based management, as it serves as a tool for periodic performance controlling (Schueler \& Krotter, 2008). The main disadvantage of the existing RI methods is that they provide no information regarding the portion of the value added attributed to operations and financing decisions separately.

In this paper, following Adsera and Vinolas (2003), we start from the principle of one value and try to bridge $\mathrm{EP}^{4}$ and APV, thus leveraging off the advantages of both methods. We call this method adjusted EP. This method is as much versatile as APV to adapt to changing capital structure, provides as much insight on periodic performance of a company as RI, and is intuitive at the same time. In particular, the shareholder value creation over a period is derived as the sum of two components: the EP relating purely to the operations of the company (we shall call it the operating EP) and the EP generated each period due to the tax savings that arise from debt financing (we shall call it the financial EP), onwards. Unlike Adsera and Vinolas (2003), the method we propose in this paper does not focus on the terminal value alone, but provides a holistic approach to measuring value throughout the forecast period.

We consider our results to be important for: (1) analysts and decision makers involved in business valuations, investments' assessments, and analysis of business performance in general; and (2) HR practitioners in terms of adjusting compensation schemes in firms where managers are evaluated and paid on the basis of EP. The remainder of the paper is organized as follows. Section 2 provides some basic algebraic equations regarding CF and RI approaches that will be used as an input in Section 3. Section 3 presents the algebraic steps for the derivation of the new key performance measure. Section 4 summarizes the paper and provides some concluding remarks.

\section{Basic Principles and Equations}

For the readers' convenience, we collect the main notional conventions, variable definitions, and abbreviations in Table 1.

As basic principles of corporate finance suggest, the following equations hold at all periods:

$$
\begin{gathered}
F C F F_{t}+T S_{t}=F C F E_{t}+F C F D_{t} \\
V_{t}^{U}+V_{t}^{T S}=E_{t}+D_{t}=V_{t}^{L}
\end{gathered}
$$

Following Vélez-Pareja and Burbano-Pérez’s (2005) formulations, we also provide some basic algebraic equations regarding $\mathrm{CF}$ approaches:

$$
\begin{gathered}
F C F F_{t}=V_{t-1}^{L} \times\left(1+\text { WACC }_{t}\right)-V_{t}^{L} \\
F C F F_{t}=V_{t-1}^{U} \times\left(1+K_{t}^{u}\right)-V_{t}^{U}
\end{gathered}
$$

\footnotetext{
3 The literature applies RI to performance measurement and valuation (Ohlson, 1995; Feltham \& Ohlson, 1995; Penman, 2007).

${ }^{4}$ In the rest of the paper, we utilize the term EP when referring to RI approaches.
} 


$$
\begin{gathered}
F C F E_{t}=E_{t-1} \times\left(1+K_{t}^{e}\right)-E_{t} \\
F C F D_{t}=D_{t-1} \times\left(1+K_{t}^{d}\right)-D_{t} \\
T S_{t}=V_{t-1}^{T S} \times\left(1+\psi_{t}\right)-V_{t}^{T S}
\end{gathered}
$$

\begin{tabular}{|c|c|}
\hline Symbol & Meaning \\
\hline$F C F F_{t}$ & Free cash flow to the firm at period $t$ \\
\hline$F C F E_{t}$ & Free cash flow to the equity at period $t$ \\
\hline$F C F D_{t}$ & Free cash flow to the debt at period $t$ \\
\hline$T S_{t}$ & Cash flow of tax shavings at period $t$ \\
\hline$V_{t}^{L}$ & Value of levered firm at period $t$ \\
\hline$V_{t}^{U}$ & Value of unlevered firm at period $t$ \\
\hline$E_{t}$ & Equity value at period $t$ \\
\hline$D_{t}$ & Debt value at period $t$ \\
\hline$V_{t}^{T S}$ & Value of tax shields at period $t$ \\
\hline WACC $_{t}$ & Weighted average cost of capital at period $t$ \\
\hline$K_{t}^{e}$ & Cost of levered equity at period $t$ \\
\hline$K_{t}^{u}$ & Cost of unlevered equity at period $t$ \\
\hline$K_{t}^{d}$ & Cost of debt at period $t$ \\
\hline$\psi_{t}$ & Discount rate of tax shields at period $t$ \\
\hline$N O P A T_{t}$ & Net operating profit after taxes at period $t$ \\
\hline$I C_{t}$ & $\begin{array}{l}\text { Invested capital at period } t \text { - it includes fixed assets, working capital, and any other operating assets that } \\
\text { contribute in } N O P A T_{t} \text {, in order to ensure consistency - as Copeland et al. (2000) suggested }\end{array}$ \\
\hline$R O I C_{t}$ & Return on invested capital at period $t$ \\
\hline$E P_{t}^{L}$ & Economic profit of levered firm at period $t$ \\
\hline$E P_{t}^{U}$ & Economic profit of unlevered firm or operating economic profit at period $t$ \\
\hline$E P_{t}^{T S}$ & Economic profit attributed to tax shields or financial economic profit at period $t$ \\
\hline$P V_{t}\left(E P^{L}\right)$ & Present value of economic profit of levered firm at period $t$ \\
\hline$P V_{t}\left(E P^{U}\right)$ & Present value of operating economic profit at period $t$ \\
\hline$P V_{t}\left(E P^{T S}\right)$ & Present value of financial economic profit at period $t$ \\
\hline g & The expected growth rate in perpetuity \\
\hline
\end{tabular}

Table 1

We also provide a basic definition of $F C F F_{t}$ that is $N O P A T_{t}$ minus investments in invested capital, i.e.:

$$
F C F F_{t}=N O P A T_{t}-\left(I C_{t}-I C_{t-1}\right)
$$

Following Copeland et al.’s (2000) formulation, we also provide some basic algebraic equations regarding RI approaches:

$$
N O P A T_{t}=R O I C_{t} \times I C_{t-1}
$$




$$
\begin{gathered}
E P_{t}^{L}=\left(R O I C_{t}-\text { WACC }_{t}\right) \times I C_{t-1} \\
V_{t-1}^{L}=I C_{t-1}+P V_{t-1}\left(E P^{L}\right)
\end{gathered}
$$

where the present value of EP of levered firm at period $t-1$ is formulated as:

$$
P V_{t-1}\left(E P^{L}\right)=\sum_{t}^{n} \frac{E P_{t}^{L}}{\prod_{t}^{n}\left(1+W A C C_{t}\right)}=\sum_{t}^{n} \frac{\left(R O I C_{t}-W A C C_{t}\right) \times I C_{t-1}}{\Pi_{t}^{n}\left(1+W A C C_{t}\right)}
$$

We note that this expression allows for a variable $W A C C_{t}$ in order to take into account changing capital structure as Copeland et al. (2000, p. 148) and Ogier, Rugman, and Spicer (2004, p. 224) suggested. We can rewrite this expression as the present value of next period EP plus the present value of EP series thereafter, i.e.:

$$
P V_{t-1}\left(E P^{L}\right)=\frac{E P_{t}^{L}+\sum_{t+1}^{n} \frac{E P_{t}^{L}}{\prod_{t+1}^{n}\left(1+W A C C_{t}\right)}}{\left(1+W A C C_{t}\right)}=\frac{E P_{t}^{L}+P V_{t}\left(E P^{L}\right)}{\left(1+W A C C_{t}\right)}
$$

Substituting $P V_{t}\left(E P^{L}\right)$ using Equation (11), we get:

$$
P V_{t-1}\left(E P^{L}\right)=\frac{E P_{t}^{L}+V_{t}^{L}-I C_{t}}{\left(1+W A C C_{t}\right)}
$$

Hence, the value of a levered firm at period $t-1$ using Equation (11) (i.e., the RI approach) takes the following form:

$$
V_{t-1}^{L}=I C_{t-1}+\frac{E P_{t}^{L}+V_{t}^{L}-I C_{t}}{\left(1+W A C C_{t}\right)}
$$

\section{Derivation of the New Method}

\section{Operating EP}

An unlevered company is an extreme case of a levered one with no debt. As such, WACC $_{t}=K_{t}^{u}$. Therefore, by substitution, the EP of an unlevered company takes the following form:

$$
\begin{gathered}
N O P A T_{t}=R O I C_{t} \times I C_{t-1} \\
E P_{t}^{U}=\left(R O I C_{t}-K_{t}^{u}\right) \times I C_{t-1} \\
V_{t-1}^{U}=I C_{t-1}+P V_{t-1}\left(E P^{U}\right)
\end{gathered}
$$

where:

$$
P V_{t-1}\left(E P^{U}\right)=\sum_{t}^{n} \frac{E P_{t}^{U}}{\Pi_{t}^{n}\left(1+K_{t}^{u}\right)}=\sum_{t}^{n} \frac{\left(R O I C_{t}-K_{t}^{u}\right) \times I C_{t-1}}{\Pi_{t}^{n}\left(1+K_{t}^{u}\right)}
$$

Or: 


$$
V_{t-1}^{U}=I C_{t-1}+\frac{E P_{t}^{U}+V_{t}^{U}-I C_{t}}{\left(1+K_{t}^{u}\right)}
$$

We shall define at this point Equation (16) as the operating EP. In other words, operating EP is the RI that is attributed to operations only.

\section{Derivation of Financial EP}

Knowing that the value of both a levered and an unlevered firm can be expressed using the RI approach, it turns out that $V_{t}^{T S}$ using Equation (2) can be re-written:

$$
\begin{gathered}
V_{t-1}^{T S}=V_{t-1}^{L}-V_{t-1}^{U}=I C_{t-1}+\frac{E P_{t}^{L}+V_{t}^{L}-I C_{t}}{\left(1+W A C C_{t}\right)}-I C_{t-1}-\frac{E P_{t}^{U}+V_{t}^{U}-I C_{t}}{\left(1+K_{t}^{u}\right)} \Rightarrow \\
V_{t-1}^{T S}=\frac{E P_{t}^{L}+V_{t}^{L}-I C_{t}}{\left(1+W A C C_{t}\right)}-\frac{E P_{t}^{U}+V_{t}^{U}-I C_{t}}{\left(1+K_{t}^{u}\right)}
\end{gathered}
$$

Working for a minute with the second part of Equation (21), we get:

$$
\frac{\left(1+K_{t}^{u}\right) \times\left(E P_{t}^{L}+V_{t}^{L}-I C_{t}\right)-\left(1+W A C C_{t}\right) \times\left(E P_{t}^{U}+V_{t}^{U}-I C_{t}\right)}{\left(1+W A C C_{t}\right) \times\left(1+K_{t}^{u}\right)}
$$

Some algebra with the numerator and we have:

$$
\left(E P_{t}^{L}-E P_{t}^{U}\right)+\left(V_{t}^{L}-V_{t}^{U}\right)-\left(K_{t}^{u}-W A C C_{t}\right) \times I C_{t}+\left(E P_{t}^{L}+V_{t}^{L}\right) \times K_{t}^{u}-\left(E P_{t}^{U}+V_{t}^{U}\right) \times W A C C_{t}
$$

Substituting Equations (10) and (16) into the first parenthesis, we get:

$$
\begin{aligned}
E P_{t}^{L}-E P_{t}^{U}= & \left(R_{O I C}-W A C C_{t}\right) \times I C_{t-1}-\left(R O I C_{t}-K_{t}^{u}\right) \times I C_{t-1} \Rightarrow \\
& E P_{t}^{L}-E P_{t}^{U}=\left(K_{t}^{u}-W A C C_{t}\right) \times I C_{t-1}
\end{aligned}
$$

Moreover, from Equation (2), we know that the expression in the second parenthesis of Equation (23) equals: $V_{t}^{L}-V_{t}^{U}=V_{t}^{T S}$.

Additionally:

$$
\left(E P_{t}^{L}+V_{t}^{L}\right) \times K_{t}^{u}=\left(R O I C_{t}-W A C C_{t}\right) \times I C_{t-1} \times K_{t}^{u}+\left(V_{t}^{U}+V_{t}^{T S}\right) \times K_{t}^{u}
$$

And:

$$
\left(E P_{t}^{U}+V_{t}^{U}\right) \times W A C C_{t}=\left(\text { ROIC }_{t}-K_{t}^{u}\right) \times I C_{t-1} \times W A C C_{t}+V_{t}^{U} \times W A C C_{t}
$$

Now reconstructing Equation (23), we get:

$$
\begin{gathered}
\left(K_{t}^{u}-W A C C_{t}\right) \times I C_{t-1}+V_{t}^{T S}-\left(K_{t}^{u}-W A C C_{t}\right) \times I C_{t}+\left(R O I C_{t}-W A C C_{t}\right) \times I C_{t-1} \times K_{t}^{u} \\
+\left(V_{t}^{U}+V_{t}^{T S}\right) \times K_{t}^{u}-\left(R O I C_{t}-K_{t}^{u}\right) \times I C_{t-1} \times W A C C_{t}-V_{t}^{U} \times W A C C_{t} \Rightarrow \\
V_{t}^{T S} \times\left(1+K_{t}^{u}\right)-\left(K_{t}^{u}-W A C C_{t}\right) \times\left(I C_{t}-I C_{t-1}\right)+\left(K_{t}^{u}-W A C C_{t}\right) \times R O I C_{t} \times I C_{t-1} \\
+\left(K_{t}^{u}-W A C C_{t}\right) \times V_{t}^{U} \Rightarrow \\
V_{t}^{T S} \times\left(1+K_{t}^{u}\right)+\left(K_{t}^{u}-W A C C_{t}\right) \times\left[R O I C_{t} \times I C_{t-1}-\left(I C_{t}-I C_{t-1}\right)+V_{t}^{U}\right]
\end{gathered}
$$


The expression in the brackets equals $\left[F_{C F F}+V_{t}^{U}\right]$, following our definition in Equation (8). Moreover, using Equation (4), we know that: $F C F F_{t}+V_{t}^{U}=V_{t-1}^{U} \times\left(1+K_{t}^{u}\right)$.

Therefore, Equation (27) takes the following form:

$$
\begin{gathered}
V_{t}^{T S} \times\left(1+K_{t}^{u}\right)+\left(K_{t}^{u}-W A C C_{t}\right) \times V_{t-1}^{U} \times\left(1+K_{t}^{u}\right) \Rightarrow \\
\left(1+K_{t}^{u}\right) \times\left[V_{t}^{T S}+\left(K_{t}^{u}-W A C C_{t}\right) \times V_{t-1}^{U}\right]
\end{gathered}
$$

Now, we can return to Equation (21). Hence:

$$
\begin{gathered}
V_{t-1}^{T S}=\frac{\left(1+K_{t}^{u}\right) \times\left[V_{t}^{T S}+\left(K_{t}^{u}-W A C C_{t}\right) \times V_{t-1}^{U}\right]}{\left(1+W A C C_{t}\right) \times\left(1+K_{t}^{u}\right)} \Rightarrow \\
V_{t-1}^{T S}=\frac{\left[V_{t}^{T S}+\left(K_{t}^{u}-W A C C_{t}\right) \times V_{t-1}^{U}\right]}{\left(1+W A C C_{t}\right)}
\end{gathered}
$$

At this point, we shall define financial EP as the spread between the cost of equity of an unlevered firm and the WACC of the firm (i.e., $K_{t}^{u}-W A C C_{t}$ ) - we shall call it the financial spread - times the value of the unlevered firm at the beginning of the period $\left(V_{t-1}^{U}\right)$ :

$$
E P_{t}^{T S}=\left(K_{t}^{u}-W A C C_{t}\right) \times V_{t-1}^{U}
$$

Financial EP is the RI at any given period attributed to the exploitation of tax benefits. Therefore, Equation (29) shall take the following form:

$$
V_{t-1}^{T S}=\frac{E P_{t}^{T S}+V_{t}^{T S}}{\left(1+W A C C_{t}\right)}
$$

Or:

$$
V_{t-1}^{T S}=\sum_{t}^{n} \frac{E P_{t}^{T S}}{\prod_{t}^{n}\left(1+W A C C_{t}\right)}=P V_{t-1}\left(E P^{T S}\right)
$$

Hence, the value of tax shields, at any single period, equals the present value of financial EP.

\section{A New Method: Adjusted EP}

Thereby, we showed that the value of any levered firm using the RI approach can also be assessed using the following formulation:

$$
V_{t-1}^{L}=I C_{t-1}+P V_{t-1}\left(E P^{U}\right)+P V_{t-1}\left(E P^{T S}\right)
$$

Or:

$$
V_{t-1}^{L}=I C_{t-1}+\sum_{t}^{n} \frac{E P_{t}^{U}}{\Pi_{t}^{n}\left(1+K_{t}^{u}\right)}+\sum_{t}^{n} \frac{E P_{t}^{T S}}{\Pi_{t}^{n}\left(1+W A C C_{t}\right)}
$$


That is, it is the sum of the firm's invested capital (at the beginning of the period) plus the present value of operating EP plus the present value of financial EP. This method if applied consistently provides identical results to EVA, EP, and CF methods ${ }^{5}$ suggested in literature and applied widely in practice.

Yet, what is more important, such method segregates operational from financial performance in any single year, thus filling in the gap between APV and RI approaches. Therefore, at any given period $t$, we can calculate the adjusted EP of a firm such that:

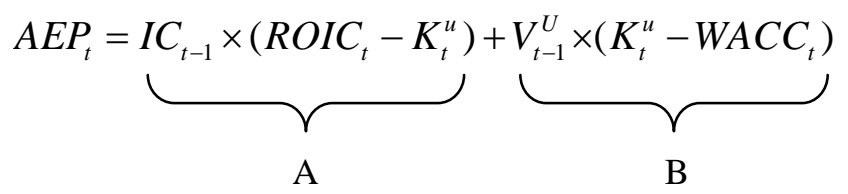

Part A is the operating EP, while Part B is the financial EP.

\section{Adjusted EP: Indicative Terminal Value Formula}

Let us assume that at period $n$ (i.e., the end of the explicit forecast period), the terminal value formula for a levered firm using the WACC approach is estimated as follows:

$$
V_{n}^{L}=\frac{F C F F_{n} \times(1+g)}{\left(W A C C_{n+1}-g\right)}
$$

Then, the suggested terminal value formulas for operating EP and financial EP so as to ensure the reconciliation of all methods are as follows:

Operating EP terminal value formula:

$$
V_{n}^{U}=\frac{I C_{n-1} \times\left(1+R O I C_{n}\right)-I C_{n}}{\left(K_{n+1}^{u}-g\right)} \times(1+g)
$$

Financial EP terminal value formula:

$$
V_{n}^{T S}=\frac{K_{n+1}^{u}-W A C C_{n+1}}{\left(W A C C_{n+1}-g\right)} \times V_{n}^{U}
$$

\section{Summary and Discussion}

In this paper, we propose a new method of measuring business performance on any single period that combines the advantages of the traditional APV and EP approaches. We do not purport to present a new theory here. The principles remain the same. The advantage of this method is that it can clearly separate and quantify the value added at any single period stemming from: (1) operations; and (2) financing decisions. In particular, a company creates value as long as: (1) It can generate returns on its invested capital greater than the opportunity cost of equity shareholders, regardless of the capital structure utilized; and (2) It can lower its WACC through the use of debt financing and the exploitation of tax shields - to the extent possible - so that it can earn a spread over the cost of unlevered equity $\left(K_{t}^{u}\right)$. In both cases, $K_{t}^{u}$ is the point of reference, hence it can be regarded as a benchmark for both operational and financing purposes.

\footnotetext{
${ }^{5}$ We note that the model's equivalence was validated using a practical numerical example, which is available upon the reader's request.
} 
It is worth noting that our method does not imply that the appropriate discount rate for tax shields should be WACC. Discounting with WACC ensures that this method produces equivalent results to existing RI and CF approaches when valuing a firm, regardless ${ }^{6}$ of the hypothesis made on the discount rate of tax shields, $\psi$. Discussion regarding the appropriate discount rate for tax shields is beyond the scope of this paper. Moreover, we should point here that the adage "the whole is the sum of the parts" does not apply in our case. The adjusted $\mathrm{EP}$ is not equal to the traditional $\mathrm{EP}^{7}$. In other words:

$$
\left(R O I C_{t}-K_{t}^{u}\right) \times I C_{t-1}+\left(K_{t}^{u}-W A C C_{t}\right) \times V_{t-1}^{U} \neq\left(R O I C_{t}-W A C C_{t}\right) \times I C_{t-1}
$$

This is because the spread over $K_{t}^{u}$ is earned upon the hypotehtical market value of the unlevered firm instead of the invested capital of the company. This also suggests that: (1) If a company creates value at an operational level (i.e., $R O I C_{t}>K_{t}^{u}$ ), then $V_{t-1}^{U}>I C_{t-1}$, thereby the spread over $K_{t}^{u}$ (i.e., the financial spread) is earned on a figure that is a multiple of the $I C_{t-1}$; and (2) If a company destroys value at an operational level (i.e., $R O I C_{t}<K_{t}^{u}$ ), then $V_{t-1}^{U}<I C_{t-1}$, thereby the financial spread is earned on a figure that is a sub-multiple of the $I C_{t-1}$. Hence, we could argue that financing decisions tend to have: (1) a multiplicative effect on the value of a company, if it creates value at an operational level; and (2) a moderate effect, if a company destroys value accordingly. Conclusively, the magnitude of the impact of financing decisions much depends on the operational performance of a company.

A final observation is that of the asymmetry between operating EP and financial EP. Operating EP can be either positive or negative, whilst the latter can only be non-negative. Put simply, financing maneuvers can only add value to a firm.

We consider that this method could be of great interest to HR executives, analysts, and decisions makers. Firms that have adopted compensation contracts with RI-based performance measures can introduce as the key performance measure of their RI Financial Managements System the new method which separates the total generated value stemming from operations and financing activities, and thus evaluate more fairly their operating managers (in the sense that most operating decisions are decentralized - so the operating manager is not responsible for financing activities and thus tax status - and most financing decisions are centralized). By doing this, the operating managers that will work toward this performance measure will have stronger incentives to improve operational efficiency, dispose of unprofitable business, and invest in value-creating business. Moreover, we believe that it will be of interest to analysts and decision makers involved in business valuations, investments' assessments, and analysis of business performance in general.

\section{References}

Adsera, X., \& Vinolas, P. (2003). FEVA: A financial and economic approach to valuation. Financial Analysts Journal, $59(2), 80-87$. Booth, L. (2002). Finding value where none exists: Pitfalls in using adjusted present value. Journal of Applied Corporate Finance, 15(1), 95-104.

Copeland, T., Koller, T., \& Murrin, J. (2000). Valuation: Measuring and managing the value of companies (3rd ed.). New York, NY: John Wiley \& Sons, Inc..

\footnotetext{
${ }^{6}$ The appropriate discount rate used for tax shields is embedded in the calculation of levered beta and WACC, effectively (see Farber, Gillet, \& Szafarz, 2007). Therefore, the appropriate discount rate for tax shields definitely affects the valuation results, but does not impact the reconciliation of the method to the traditional RI or CF methods used for valuing firms.

${ }^{7}$ At the extreme, the two would equal if either ROIC $_{t}=K_{t}^{u}$ at all times (which implies that no value is added at an operational level, therefore, $V_{t-1}^{U}=I C_{t-1}$ ) or $K_{t}^{u}=W A C C_{t}$ (i.e., in the case of an unlevered company).
} 
Farber, A., Gillet, R., \& Szafarz, A. (2007). A general formula for the WACC: A reply. Centre Emile Bernheim Research Institute in Management Sciences (WP-CEB 07-004), Solvay Business School.

Feltham, G. A., \& Ohlson, J. A. (1995). Valuation and clean surplus accounting for operating and financial activities. Contemporary Accounting Research, 11(2), 689-731.

Gross, S. (2006). Banks \& shareholder value. DUV Gabler Edition Wissenschaft.

Luehrman, T. A. (1997). Using APV: A better tool for valuing operations. Harvard Business Review, 75, 145-154.

Myers, S. C. (1974). Interactions of corporate financing and investment decisions - Implications for capital budgeting. Journal of Finance, 29(1), 1-25.

Ogier, T., Rugman, J., \& Spicer, L. (2004). The real cost of capital: A business field guide to better financial decisions. FT: Prentice Hall.

Ohlson, J. A. (1995). Earnings, book values, and dividends in equity valuation. Contemporary Accounting Research, 11(2), 661-687.

Penman, S. (2007). Financial statement analysis and security valuation (3rd ed.). McGraw-Hill.

Schueler, A., \& Krotter, S. (2008). The link between residual income and value created for levered firms: A note. Management Accounting Research, 19(3), 270-277.

Vélez-Pareja, I., \& Burbano-Pérez, A. (2005). Consistency in valuation: A practical guide. Working paper submitted to the II Simposio de Docentes de Finanzas Bogotá. 